\title{
WORDS PRODUCTION BASED ON MEMORY RECALL THROUGH NARRATIVE WRITING
}

\section{(A Descriptive Qualitative Study)}

\author{
Audi Yundayani \\ STKIP Kusuma Negara, Jakarta \\ audi_yundayani@stkipkusumanegara.ac.id
}

\begin{abstract}
APA Citation: Yundayani, A. (2019). Words Production Based on Memory Recall through Narrative Writing: A Descriptive Qualitative Study. Journal of English Language and literature, 4(1), 95-101, DOI 10.37110/jell.v4i01.73
\end{abstract}

\begin{abstract}
Producing words refers to the mental process of retrieval of information that has been previously encoded and stored in the human brain. The aim of this research is to identify and describe words production based on memory recall through narrative writing. This research is a qualitative approach by using a descriptive qualitative method. Data and data sources are students' narrative writing and strengthened by a semi-structured interview. The research finding shows that word production based on memory recall through narrative writing is influenced by some factors. They are 1) psychological factors, like motivation, 2) frequency of words using, 3) the understanding of the concept, and 4) schemata that is related to stored memory. These findings should be a guideline for the instructor to give a stimulus in developing students' words production.
\end{abstract}

Key words: narrative writing; word production; memory recall

\section{INTRODUCTION}

Word is an important aspect of presenting the language. It is important for the language user to have the word mastery list in order to explore and present their idea and concept. People believe that the word knowledge is a vital part of the knowledge of any language, whether it is a mother tongue or a foreign language (Šišková, 2012). In knowing the word, Nation (2001) stated three main areas, (1) knowing the form whether spoken, written or word parts); (2) the meaning that covers the connection between the form and the meaning, the concept and its referents, and the associations connected with a particular word; (3) the use that concerns how the word functions grammatically, its collocations and any possible restrictions on use. Knowing the form, the meaning and the use of the words is the important aspect in producing the words.

Language can be seen as a part of the cognitive self that should be classified in one's memories. Nelson (1993) believed that autobiographical memories are personal life experiences that often have a high degree of self - concept importance. A phenomenon which is known as language-dependent recall (LDR) described the language used during recovery is likely to generate memories containing the same language's linguistic properties for bilingual people. Marian \& Neisser (2000) stated that language can have strong contextual effects. It can serve not only as an external context (words are spoken 
aloud) but also as an internal or mental context (a language of thought). In addition, Schrauf (2000) defined two mechanisms in memory, one is recall, in order to initiate the response and one is recognition, the term to assess the accuracy of the ongoing response. The recall is facilitated by the similarity between memory properties (encoding context) and recovery situation properties. The repeated practice of these precise responses gave the right response to sensations experience. Words production related to schemata. All of the information stored in the one's memory can be recalled through the stimulus given.

A media to deliver the message can be done through writing. This skill can be seen as an inscription; a language in a spatial medium. Writing takes language out of constraints and immediacy of time and arranges it hierarchically (Knapp \& Watkins, 2005). Narrative writing is a story told whether it is a fiction or non-fiction. It can be seen as a story told to make a point (McCrimmon, 1984). It is believed as the most powerful ways of communicating with others. It tells the story and should have interesting content (Meyers, 2005). Through the narrative writing, students tell a story about something that happened to them and in such a way the reader learns a lesson or gains insight and there are allowed to express themselves in a creative way.

Many previous experts explored students' lexical richness that covered words production. Through the different ways, they explored this related topic and found the findings, such as, Laufer, B., \& Nation, I.S.P. (1995) who explored the students' lexical richness in L2 written production or Siskova, Z (2012) with students' lexical richness in EFL students' narratives. Comparing with them, this article aims to describe students' words production based on memory recall through narrative writing by investigating the number of produced words on students' narrative writing, classifying the words' type and exploring students' background. By the end, the findings conclude that some factors influence students' word production in the term of psychological factors; frequency of words using; the understanding of the concept; schemata that is related to stored memory.

\section{METHOD}

The study used descriptive qualitative research methods. This research was conducted by involving 10 students. They were asked to make narrative writing in 20 minutes. Before students started to write, they were conditioned to remember their experience of being disappointed, what happened, how it happened, what they felt and other things related to memory recall.

After students' writing had been collected, then the number of produced words was manually calculated and grouped based on the word type (part of speech). A table and graph were made to describe the writing result. To support the data, a semi-structured interview was conducted to the students who have the highest and lowest word production. The word production occurs if there has been a previous comprehension. The results of the study were presented in a qualitative descriptive manner.

\section{FINDINGS AND DISCUSSION}

In this section, the author presents the results of the research related to the calculation of the number and the types of produced words through narrative writing. 
Table 1. The number and the types of produced words

\begin{tabular}{|cccccc}
\hline & \multirow{2}{*}{$\begin{array}{c}\text { The number of } \\
\text { produced words }\end{array}$} & Verb & Noun & Adjective & Adverb \\
\cline { 3 - 6 } & & & & & \\
& & 49 & 38 & 36 & 35 \\
\hline Student 1 & 158 & 41 & 38 & 35 & 32 \\
\hline Student 2 & 146 & 51 & 57 & 37 & 38 \\
\hline Student 3 & 183 & 43 & 45 & 31 & 37 \\
\hline Student 4 & 156 & 52 & 42 & 30 & 35 \\
\hline Student 5 & 159 & 61 & 50 & 36 & 38 \\
\hline Student 6 & 185 & 44 & 35 & 32 & 38 \\
\hline Student 7 & 149 & 48 & 53 & 32 & 35 \\
\hline Student 8 & 168 & 49 & 47 & 39 & 40 \\
\hline Student 9 & 175 & 46 & 43 & 28 & 28 \\
\hline Student 10 & 145 & 484 & 448 & 336 & 356 \\
\hline
\end{tabular}

Graph 1. The number of produced words

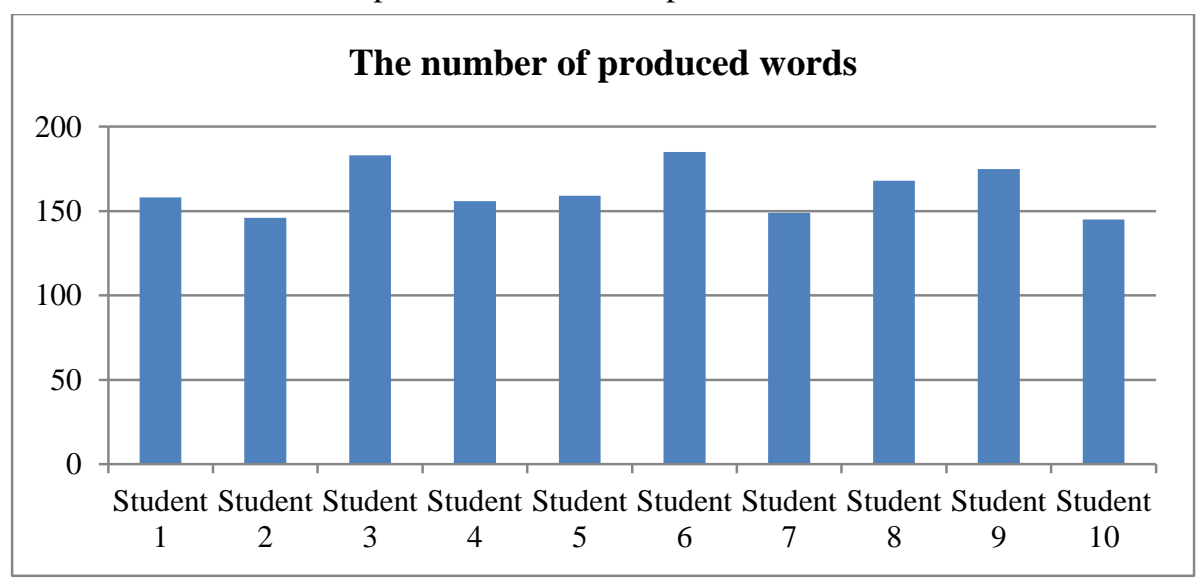

Graph 2. The number of produced words based on parts of speech

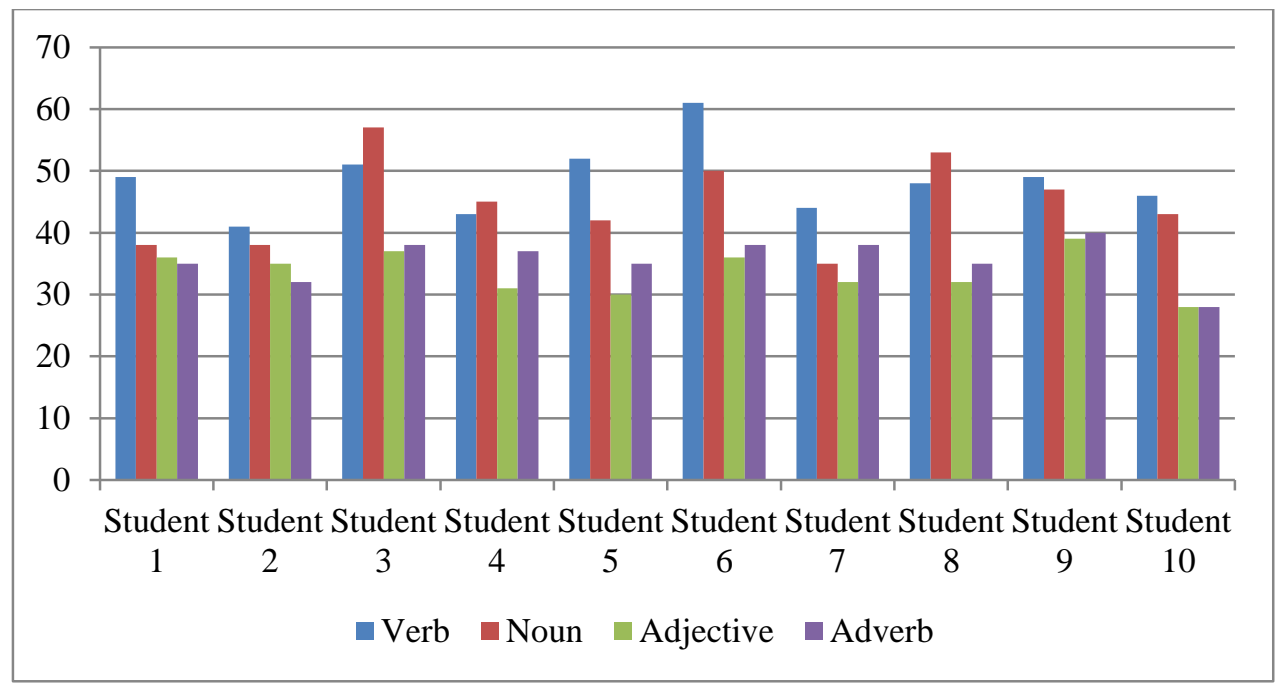


The above descriptions show the number and types of produced words through narrative writing. During 20 minutes, there were very different differences in the number of words produced by 10 respondents, including the difference in the number of words used, even though the theme and time given were the same. All of the respondents were women with ages ranging from 21-23 years. Student number 6 was a student who has the highest word production and student number 10 was a student who has the lowest word production. To strengthen the discussion of research, researchers conducted a semi-structured interview with students who had the highest and lowest word production. Based on the below interview script, it was concluded that student number 6 has a number of backgrounds that influenced the number of word production,

Table 2. The interview script with the highest score student - Student No. 6

\begin{tabular}{|c|c|c|}
\hline \multicolumn{2}{|r|}{ Interview Script } & Code \\
\hline $\mathbf{Q}$ & What makes you want to write about the theme given? & \multirow[b]{2}{*}{ IS06-1 } \\
\hline A & $\begin{array}{l}\text { Because you gave the assignment and you promised to give an additional score for } \\
\text { the last mid-test. }\end{array}$ & \\
\hline $\mathbf{Q}$ & Do you like to share stories about what you feel? & \multirow[b]{2}{*}{ IS06-2 } \\
\hline A & $\begin{array}{l}\text { Yes. I always tell my mother. Sometimes with younger siblings, but rarely. } \\
\text { Frequently with friends. }\end{array}$ & \\
\hline $\mathbf{Q}$ & What is your hobby? & \multirow{2}{*}{ ISO6-3 } \\
\hline A & I like reading and writing my diary. SometimesI love watching movie at cinema. & \\
\hline $\mathbf{Q}$ & What kind of book do you like to read? & \multirow{2}{*}{ IS06-4 } \\
\hline A & I love all, but the most is novel. & \\
\hline $\mathbf{Q}$ & Tell me about your diary writing & \multirow{2}{*}{ IS06-5 } \\
\hline A & Almost every day I write diary. Usually about experience or what I feel. & \\
\hline $\mathbf{Q}$ & What experience disappointed you most? & \multirow[b]{2}{*}{ ISO6-6 } \\
\hline A & $\begin{array}{l}\text { What huh? Mmmh, a lot actually. But the most disappointing thing was when I } \\
\text { didn't make it to the university I wanted. I am disappointed with myself. I lack } \\
\text { focus. Too much playing, even if I'm serious, I'm sure I can. }\end{array}$ & \\
\hline $\mathbf{Q}$ & What do you do if you are disappointed? & \multirow{2}{*}{ ISO6-7 } \\
\hline A & $\begin{array}{l}\text { Usually I confide in my mother or my close friends. Then I write again what I feel } \\
\text { in diary. }\end{array}$ & \\
\hline $\mathbf{Q}$ & Do you like to remember things that happened in the past? & \multirow{2}{*}{ ISO6-8 } \\
\hline A & $\begin{array}{l}\text { Yes. I usually re-read the contents of my diary I wrote first. So [I] laugh myself and } \\
\text { [I] remember the same as before. }\end{array}$ & \\
\hline $\mathbf{Q}$ & Do you get valuable lessons from disappointing experiences? & \multirow[t]{2}{*}{ IS06-9 } \\
\hline A & Yes, sometimes. & \\
\hline $\mathbf{Q}$ & What makes do you like to write diaries? & \multirow[t]{2}{*}{ IS06-10 } \\
\hline A & I became calm after writing. Then, let me have a memory. & \\
\hline
\end{tabular}

The above statement from student number 6 above proves that basically word production is influenced by several things, including the frequency of words and the more often meaning that a word is used, the faster we can call it when we need it. This is illustrated by repetition of the use of words in storytelling activities, reading which her hobby became and diary writing activities.

If this is seen based on memory, then what is said by Clark and Clark and Engal in Soenjono (2003) that memory will be formed and used through 3 stages, input, storage, and 
output. Especially at the input stage, generally we accept it from oral or written form, and then we give an interpretation of the input to understand it. Usually we pay attention to the meaning not words, so that what is stored in memory is not a word that is heard or read but the content or message of the whole words, so if we have to restate what has just been heard or read, we will not use the word the exact word for input. This is reflected in the following quotations,

- Yes. I always tell [my stories] to my mother. Sometimes with younger siblings, but rarely. Frequently with friends

- Almost every day I write a diary. Usually about [my] experiences or what I feel.

- What huh? Mmmh, a lot actually. But the most disappointing thing was when I didn't make it to the university I wanted. I am disappointed with myself. I lack focus. Too much playing, even if I'm serious, I'm sure I can.

- Usually I confide in my mother or my close friends. Then I write again what I feel in the diary.

- Yes. I usually re-read the contents of my diary I wrote first. So [I] laugh myself and [I] remember the same as before.

- I became calm after writing. Then, let me have a memory.

The previous statements show that student number 6 has habituation related to the frequency of words using, both through the habit of telling stories and rewriting experiences gained by writing diaries, so that word production becomes more compared to student number 10 . The following is an interview script with the student number 10 related to the frequency of words using.

Table 3. The interview script with the lowest score student - Student No. 10

\begin{tabular}{|c|c|c|}
\hline & Interview Script & Code \\
\hline $\mathbf{Q}$ & Do you like to share stories about what you feel? & \multirow{2}{*}{ IS10-1 } \\
\hline A & Sometimes I like to confide with friends, sometimes also with my parents & \\
\hline $\mathbf{Q}$ & What are your hobbies? & \multirow{2}{*}{ IS10-2 } \\
\hline A & I like to swim. & \\
\hline $\mathbf{Q}$ & Do you like to read? & \multirow{2}{*}{ IS10-3 } \\
\hline A & No. & \\
\hline $\mathbf{Q}$ & Do you like writing? & \multirow{2}{*}{ IS10-4 } \\
\hline A & No. & \\
\hline $\mathbf{Q}$ & Why don't you like to read or write? & \multirow[b]{2}{*}{ IS10-5 } \\
\hline A & $\begin{array}{l}\text { I like to be bored. I prefer outdoor activities, such as swimming, basically there is } \\
\text { movement }\end{array}$ & \\
\hline $\mathbf{Q}$ & How do you feel about writing assignment? & \multirow{2}{*}{ IS10-6 } \\
\hline A & I don' like writing. It is difficult and it makes me sleepy. & \\
\hline $\mathbf{Q}$ & Do you like reading and telling people about anything? & \multirow{2}{*}{ IS10-7 } \\
\hline A & No. I prefer to spend my time by doing sport and i prefer to keep my own story. & \\
\hline
\end{tabular}

The script interview on table 3 describes that student number 10 tends to never express what is felt, either in written or spoken. The person concerned does not like activities related to repetition of word production, such as does not like reading, and does not like writing and sometimes telling about the experience that is felt. This has an impact on the number of produced words. These habituation differences affect the output process, in this case in the process of memory recall, the process by which we are asked to express something that we have seen or heard before. Clark and Clark in Soenjono (2003) stated that we utilize three external pieces of information when conducting a recall, (1) by 
utilizing knowledge about the language that is owned; (2) by utilizing knowledge about the world; (3) by utilizing knowledge about discourse conventions.

Word production is influenced by experience or memory and the individual's ability to understand concepts and the meaning of a word. It depends on the context in which someone thinks. In order to produce a word, it is important not just to recognize a sequence of sounds, but achieve near-perfect recall of it (Krishnan, S., Watkins, K. E., \& Bishop, D. V. M., 2017). This means that each individual indirectly produces a different number of words because they are associated with different abilities to understand concepts and meanings related to the context in which someone thinks. This is reflected in the comparison of the number of words produced. The 10 respondents who were all women produced more verbs than other types of words. There is a tendency for verb production to be included in the mental subcategory. This can be associated with an understanding of the context that was thought and stored in memory. If it is associated with processes that occur in the brain, words and meanings that have been seen, heard or even felt, will be stored, compiled, organized and re-known in our brain. This affects the production of the words we produce, including an understanding of meaning. Past experience has an important role in word production which is reflected in the number of words produced by students. Themes related to past experiences that must be written in the form of narrative writing make them recite words based on past memory contributions.

The above description is related to what was conveyed by Cook (1989) in the definition of a concept. It can be seen as a mental representation of a thing that has a characteristic. In this case, the existence of a scheme described as a cognitive construction as a part of long- term memory. It can be seen as past experience and stored in long-term memory, not in the form of words but concepts or meanings. So if the same thing is conveyed again, then the possibility of differences in word production and word types are very easy, even though the meaning or concept remains the same. Schemata have an important role in the cognitive process and make us focus to pay attention, understand, interpret, remember, make conclusions, determine goals and expectations, determine reasons and solve problems. The experience referred to not only limited the experience of feeling something but also related to English language proficiency, in this case, the vocabulary possessed by English learners as a foreign language.

The findings show that student number 6 has activities that influence the experience of memory. The habit of telling stories and writing diaries is the output of memory recall. The input is an experience that is stored in memory. The opposite thing we find in students number 10 who tend to not want to remember the experiences that have occurred. She has no motivation, especially internally, which has an impact on the low number of word production. This is reinforced by his dislike of storytelling and writing so that the frequency of limited word production results in limited input and storage in memory. By the end, the output or quantity of word production is limited.

\section{CONCLUSION}

Word production based on memory recall will occur if it is influenced by a number of things, such as frequency, ambiguity, and semantic proximity, while input factors and understanding of concepts also have an impact on word production. Not only that, but also the existence of schemata also has a role in the number of produced words. There are past contributions stored in long-term memory, not words, but meanings or concepts.

Words can be produced if they have been stored in the previous memory. A new word 
will be produced if there is prior comprehension. In this process, we receive input and it is stored in memory. When it is produced, the stored words are searched and then it is used. Psychological factors also play a role in the amount of produced words, intelligence, resourcefulness, motivation and creativity. These have an impact on a person's ability to do memory recall.

\section{REFERENCES}

Dardjowidjojo, S. (2003). Psikolinguistik: Pengantar Pemahaman Bahasa Manusia. Jakarta: Yayasan Obor Indonesia.

G. Cook,. Discourse in language teaching. (1989). A schema for teacher education. Oxford: Oxford university Press.

Knapp, P \& Watkins, M. (2005). Genre, Text, Grammar: Technologies for Teaching and Assessing Writing. Sidney: University of New South Wales.

Krishnan, S., Watkins, K. E., \& Bishop, D. V. M. (2017). The effect of recall, reproduction, and restudy on word learning: a pre-registered study. BMC Psychology, $5(1)$ doi:10.1186/s40359-017-0198-8.

Laufer, B., \& Nation, I.S.P. (1995). Lexical richness in L2 written production: can it be measured? Applied Linguistics $16,307-322$.

Marian, V., \& Neisser, U. (2000). Languagedependent recall of autobiographical memories. Journal of Experimental Psychology, 129, 361-368. doi:10.10 37//0096-5.129.3J61.

McCrimmon, J. M. (1984). Writing with a purpose. Boston: Houghton Mifflin Company.

Meyers, A. (2005). Gateways to academic writing. New York: Pearson Education, Inc.

Nation, I.S.P. (2001). Learning Vocabulary in Another Language. Cambridge: Cambridge University Press.

Nelson, K. (1993). The psychological and social origins of autobiographical memory. Psychological Science, 4, 7$14 . \quad$ doi:10.1111/j.14679280.1993.tb00548.x.

Schrauf, R. W. (2000). Bilingual autobiographical memory: Experimental studies and clinical cases. Culture and Psychology, 6, 387-417.

doi:10.1177/1354067X0064001.

Siskova, Z (2012). Lexical richness in EFL students' narratives. Language Studies Working Papers, University of Reading, 4, pp. $26-36$. 